\title{
DAMPAK EKOOGI PENABANGAN BATU KAPUR SEBAGAI BAHAN DASARPEBUATANSEEN DIGUNUNG SADENG KECAATAN PUGER, KABUPATEN JEBER
}

\author{
M Abdul Gofur ${ }^{1}$, I Gede Astra wesnawa ${ }^{2 *}$
}

Prodi Pendidikan Geografi, Universitas Pendidikan Ganesha, Indonesia

\section{A R T I C L E I N F O}

\section{Article history:}

Received 19 Agustus 2018

Received in revised form

6 November 2018

Accepted 12 November 2018

Available online 30

November 2018

\section{Kata Kunci:}

batu kapur

dampak ekologi

penambangan

Keywords:

Terdiri dari 3 - 5 kata dan setiap kata kunci dimulai dengan baris baru

\begin{abstract}
A B S T R A K
Penelitian ini bertujuan: (1) menjelaskan karakteristik batu kapur yang ada di Gunung Sadeng, Kecamatan Puger, Kabupaten Jember. (2) menjelaskan proses penambangan batu kapur di Gunung Sadeng, Kecamatan Puger Kabupaten Jember. Dan (3) menganalisis dampak ekologi akibat dari penam- bangan batu kapur di Gunung Sadeng, Kecamatan Puger, Kabupaten Jember. Hasil penelitian menunjukkan (1) karakteristik jenis batu kapur di Gunung Sadeng yaitu berjenis Chalky limestoneyang (2) Proses penambangan di Gunung Sadeng terdiri dari 7 tahapan, A. Tahap penyelidikan B. Pembabatan dan penebangan. C. Pengupasan lapisan penutup. D. Penggalian dan pembe- rairan. E. Pemuatan F. Pengangkutan G. Pembakaran batu kapur dan (3) Dampak ekologi penambanga berdampak terhadap unsur biotik dan abiotik. Unsur biotik di antaranya manusia yang terkena dampak penambangan berupa tergangunya saluran pernapasan akibat debu dan asap pembakaran, semakin berkurangnya vegetasi yang
\end{abstract} berimbas kepada kerusakan lingkungan Gunung Sadeng, dan terganggunya kelestarian fauna karena ekosistem mereka rusak, dampak terhadap unsur abiotik brupa berubahnya sifat fisik, kimia dan biologi tanah.

\section{A B S T R A C T}

The aims of this research are (1) Explain the characteristics of limestone in Mount Sadeng, Puger Sub-district, Jember District. (2) Explains the limestone mining process at Mount Sadeng, Puger District, Jember District. (3) Analyze the ecological impacts resulting from limestone mining at Mount Sadeng, Puger Sub-district, Jember District. With regard to the purpose of research, this study uses descriptive qualitative research design with sample number 93 is divided into two types of small-scale penbang 19 and 73 large-scale miners. The data collected in this study are primary data and secondary data, method of data collection in this study were questionnaires, observation sheets and unstructured interviews. The results showed (1) based on results from respondents through questionnaires and direct observation of spaciousness by researchers characteristics of limestone in which manifold Chalky Mount Sadeng limestoneyang (2) The mining process on Mount Sadeng consists of 7 stages, A. Stage B. The clearing investigation and logging. C. Stripping the cover. D. Excavation and watering. Loading F. Conveyance E. G. Burning limestone and (3) The ecological impacts of mining impact on biotic and abiotic elements. Biotic elements among humans affected by mining in the form respiratory disrupted tract due to dust and fumes of combustion, the decrease in vegetation which impact on environmental degradation Mount Sadeng.

\footnotetext{
* Corresponding author.

E-mail addresses: gofurabdul229@yahoo.com (Penulis Pertama), gede astrawesnawa@yahoo.co.id (Penulis Kedua)
} 


\section{Pendahuluan}

Indonesia secara regional berada pada dua buah lempeng besar yaitu Lempeng Pacifik di Utara dan Lempeng Australia di Selatan. Akibat tumbukan kedua lempeng tersebut, telah menempatkan Indonesia menjadi salah satu wilayah Negara yang rawan dengan bencana gempa bumi, tsunami dan letusan gunung berapi. Namun, dibalik bencana alam akibat tumbukan dua lempeng tersebut, membawa hikmah yang tak ternilai harganya. Akibat aktifitas pergerakan kedualempeng tersebut pulalah akhirnya menghasilkan tatanan tektonik yang lengkap. Kondisi geologi demikian mendukung pembentukan minaeralisasi berbagai mineral atau bahan galian berharga sebagai anugerah Tuhan YME yang patut disyukuri, misalnya mineral logam dan lain-lain (Manik, 2010).

Proses mineralisasi adalah salah satu keuntungan dari bencana yang diakibat- kan tumbukan kedua lempeng, secara nyata telah menempatkan Indonesia sebagai Negara kaya akan berbagai macam mineral atau bahan galian. Sumberdaya mineral atau bahan galian yang terkandung di Indonesia sebenarnya sudah diusahakan sejak jaman Hindia Belanda, seperti tambang emas di Cikotok yang baru dilakukan penutupan diakhir tahun 1980-an, kemudian tambang bauksit di Pulau Bintan, tambang Batubara di Sumatera Barat dan lain-lain. Melihat sejarah pertambangan Indonesia yang sudah berjalan cukup lama, merupakan modal dasar pembangunan dalam rangka mencapai tujuan sebesar-besarnya untuk kemakmuran rakyat (Manik, 2010).

Usaha Pertambangan adalah sebagian atau seluruh tahapan kegiatan dalam rangka penelitian, pengelolaan dan pengusahaan mineral dan batubara yang meliputi penyelidikan umum, eksplorasi, studi kelayakan, konstruksi, penambangan pengolahan dan pemurnian, pengang kutan dan penjualan serta kegiatan pasca tambang (Pasal 1 butir 6 Undang-Undang No.4 Tahun 2009 tentang Pertambangan Mineral dan Batubara).

Berdasarkan PP No 25 tahun 1984-1996 no 126, bahan galian digolong kan menjadi 3 golongan, yaitu: bahan galian strategis (golongan A) (Antrasit, semua jenis batubara; Besi, Titanium, Vanadium, Nikel, Kobalt, Mangan, dan Timah putih; Throilim, Radium, Uranium, Zirkon, Klorit; Minyak bumi, Lilin, (semua jenis Bitumen cair); Aspal ( semua jenis Bitumen padat), Bahan Galian Vital (Golongan B) (Emas, Platina, Air Raksa, Perak; Belerang, Antimun, Bismut; Magnesium, Korium, Calsium), Bahan Galian tidak termasuk strategis dan vital (Golongan C) (Batu kapur, batupasir, tanah liat, dll) (Maskuri, 2010).

Batu kapur merupakan salah satu bahan galian $\mathrm{C}$ yang banyak terdapat di Indonesia. Pegunungan kapur di Indonesia menyebar dari barat ke timur mulai dari pegunungan di Jawa Tengah hingga ke Jawa Timur, Madura, 
Sumatra, dan Irian Jaya. Besarnya potensi tersebut diiringi pula dengan konsumsi batu kapur yang besar untuk memenuhi kebutuhan manusia. Secara umum segala benda yang ada di rumah dan kantor membutuhkan batuan kapur dengan fase tertentu baik langsung maupun tidak langsung. Batu kapur ialah batuan sedimen yang terdiri dari mineral Calcite (kalsium carbonate). Sumber utama dari Calcite adalah organisme yang berasal dari laut dan menghasilkan kulit kerang yang keluar ke air dan terbawa hingga bawah samudera sebagai pelagic ozone. Calcite sekunder juga dapat terdeposisi oleh air meteroik tersupersa turasi (air tanah yang presipitasi material di gua). Ini menciptakan speleothem seperti stalagmite dan stalaktit. Bentuk yang lebih jauh terbentuk dari Oolite (batu kapur Oolitic) dan dapat dikenali dengan penampilannya yang "granular". Batu kapur membentuk 10\% dari seluruh batuan sedimen (Algunadi, I., Astawa, I. M., 2010).

Sampai saat ini pemanfaatan batu kapur sebagai bahan dasar pembuatan semen masih sangat produktif digunakan terbukti dengan adanya proses ekspor Indonesia pernah menduduki posisi ke 2 setelah Thailand dan menduduki posisi ke 4 setelah negara Thailand, Jepang dan Turki,pada kegiatan inpor Indonesia tidak termasuk jajaran negara yang banyak menginpor semen dan pada kegiatan konsumsi semen Indonesia merupakan negara yang termasuk pengosumsi terbesar setelah Thailand di ASEAN dan pernah menduduki peringkat ke 3 setelah Thailand dan Vietnam, Hal ini sangat membuktikan bawasanya semen merupakan bahan yang sangat penting bagi keberlangsungan hidup manusia yang berguna sebagai bahan utama pembangunan rumah atau pembangunan fisik lainya. Semen merupakan zat yang digunakan untuk merekatkan batu, bata, batako maupun bahan bangunan lainya (Hakim, 2015).

Pengelolaan lingkungan merupakan hal yang sangat penting dilakukan, mengingat bahwa manusia selalu berusaha memaksimalkan segala perwujudan keinginannya dan seringkali dengan cara yang secepat-cepatnya, sehingga cenderung mengorbankan kepentingan lingkungan hidupnya (Purnaweni Hartuti, 2014). Keadaan itulah yang menyebab kan sampai saat ini penambangan batu kapur sangat gencar dilakukan di kawasan karst diseluruh Indonesia, salah satunya di Gunung Sadeng, Kecamatan Puger, Kabupten Jember, Jawa Timur.Jember merupakan salah satu kabupaten yang terletak di Provinsi Jawa Timur dan secara geografis merupakan daerah deretan pegunungan kapur selatan, sehingga Kabupaten Jember memiliki sumberdaya bahan galian C, yaitu batu kapur yang berlokasi di Gunung Sadeng, Kecamatan Puger.Gunung Sadeng rnerupakan perbukitan kompak (batu kapur) yang secara administratif berada di Desa Grendeng, Puger Kulon dan Puger Wetan, Kecamatan Puger Kabupaten Jember Provinsi Jawa Timur. Gunung memiliki ketinggian 245 m dengan luas wilayah + 285 
Ha. Batu kapur Gunung Sadeng merupakan bahan galian industri yang cukup potensial di Kecamatan Puger karena cadangan depositnya yang mencapai 475.800.000 ton dengan luas areal tambang 183 Ha berkualitas putih super atau high grade (Bapeda Jember, 2009).

Proses berlangsungnya kegiatan penambangan tentu tidak hanya dampak positif yang dihasilkan dampak negatif berupa kerusakan lingkungan selalu menjadi masalah dalam setiap industri penambangan. Salah satu kerusakan lingkungan yang rusak akibat adanya penambangan batu kapur di Kecamatan Puger adalah ekologi yang ada dikawasan Gunung Sadeng, Akibat adanya kegiatan penambangan batu kapur sebagai bahan dasar pembuatan semen yang dilakukan oleh warga Kecamatan Puger dan pekerja pabrik salah satu dampaknya adalah merusak kawasan ekologi yang ada di sekitar Gunung Sadeng, Kurangnya pengetahuan warga Kecamatan Puger terhadap pentingnya menjaga lingkungan agar tidak berdampak pada rusaknya ekologi yang ada di Gunung Sadeng tergolong sangat rendah, kebanyakan warga dan pekerja pabrik di Kecamatan Puger hanya mementingkan dampak positifnya saja berupa penghasilan yang dihasilkan dari penambangan batu kapur, terbukti dengan peralatan yang mereka gunakan yang masih sederhana (Satriyani, 2014).

Kawasan kapur adalah kawasan yang mudah rusak "fragil" serta memiliki daya lenting yang sangat kecil kondisi demikian mengharuskam kawasan tersebut harus direncanakan dengan sangat matang sehingga kerusakan lingkungan dapat diminimalisir. Apabila kerusakan kawasan kapur di Gunung Sadeng terjadi otomatis akan berdampak pada keseimbangan ekologi yang tidak lagi seimbang karena adanya kerusakan kawasan yang merupakan rumah dari ekosistem yang ada kawasan Gunung Sadeng Kecamatan Puger, Menimbang kawasan kapur yang mudah rusak dan mempunyai daya lenting yang rendah yang kerusakaanya berdampak pada kesimbnagan ekologi yang ada di Gunung Sadeng. Pengeloaan lingkungan hidup merupakan upaya terpadu untuk melestarikan fungsi lingkungan hidup yang meliputi kebijaksanaan, penataan, pemanfaatan, pengembangan, pemeliharaan, pemanfaatan, pengembangan, pemeliharaan, pemulihan, pengawasan, dan pengendalian lingkungan hidup (Busroh, 2014). Demi mementingkan kepentingan dimasa mendatang agar dampak ekologi yang ditimbulkan tidak semakin parah, dan agar kawasan karst di Gunung Sadeng Kecamatan Puger dapat terus dimanfaatkan. Maka penulis tertarik untuk meneliti "Dampak Ekologi Penambangan Batu Kapur Sebagai Bahan Dasar Pembuatan Semen di Kecamatan Puger, Kabupaten Jember." 


\section{Metode}

Penelitian ini menggunakan rancangan penelitian deskriptif kualitatif. data dalam penelitian ini bersifat deskriptif, maksudnya data dapat berupa gejala-gejala yang di kategorikan ataupun dalam bentuk lainnya, seperti foto, dokumen, dan catatan-catatan lapangan saat penelitian berlangsung (Sugiyono, 2011).

Berdasarkan permasalahan yang dikemukakan data yang dikumpulkan dalam penelitian ini adalah data primer dan data sekunder. Jumlah populasi dalam penelitian ini sebanyak 93 sampel yang terdiri atas penambang skala besar dan penambang skala kecil, berdasarkan jumlah populasi , pengambilan sampel akan menggunakan "proporsional Random Sampling" jumlah sampel masing-masing sub populasi akan diambil secara proporsional dengan mengacu pada ketentuan (Arikunto, 2011).

Objek dalam penelitian ini adalah ekologi yang ada dikawasan gunung Sadeang, dalam hal ini kawasasan ekologi yang rusak akibat dari penambangan batu kapur. Subjek dalam penelitian ini yaitu aktifitas penambangan batu kapur yang menyebabkan rusaknya ekologi di kawasan karst gunung Sadeng. Data yang diperoleh terkait dengan karakteristik batu kapur, proses penambangan dan dampak ekologi yang ada di Gunung Sadeng kecamatan Puger, menggunakan analisis deskriptif kualitatif dengan pendektan ekologi

\section{Hasil dan Pembahasan}

\subsection{Karakteristik bayu kapur di Gunung Sadeng}

Berdasarkan ketiga jenis batu kapur yang dijadikan pilihan ganda oleh peneliti diantaranya: Chalky limestone, Coquina, Fossiliferous Limestone. Dan masyarakat yang berkesempatan mengisi kuisioner rta-rata dari 93 orang, 71 diantaranya memilih jenis batu kapur Chalky limestone. Namun pada nomornomor tertentu pada 30 pertanyaan yang ada di kuisioner masyarakat harus dijelaskan maksud dari pertanyaan yang ada di kuisioner tersebut, salah satunya adalah no 1 yang membahas mengenai jenis batu kapur, karna ketebatasan pengetahuan mereka sehiga peneliti harus menjelaskan terlebih dahulu bahasa yang dianggap asing di telinga masayarakat yang berkerja sebagai penambang batu kapur, diantarnya peneliti menjelaskan satu persatu maksud dari jenis batu kapur Chalky limestone, Coquina, Fossiliferous Limestone. Dan hasilnya sebagian besar masyarakat memilih jenis batu kapur Chalky limestoneyang berada di Gunung Sadeng Kcamatan Puger. dibaah ini merupakan gambar jenis batu kapur Chalky limestone yang ada di Gunung Sadeng. untuk lebih jelasnya mengenai jenis batu kapur di Gunung Sadeng dapat diihat pada gambar dibawah ini 


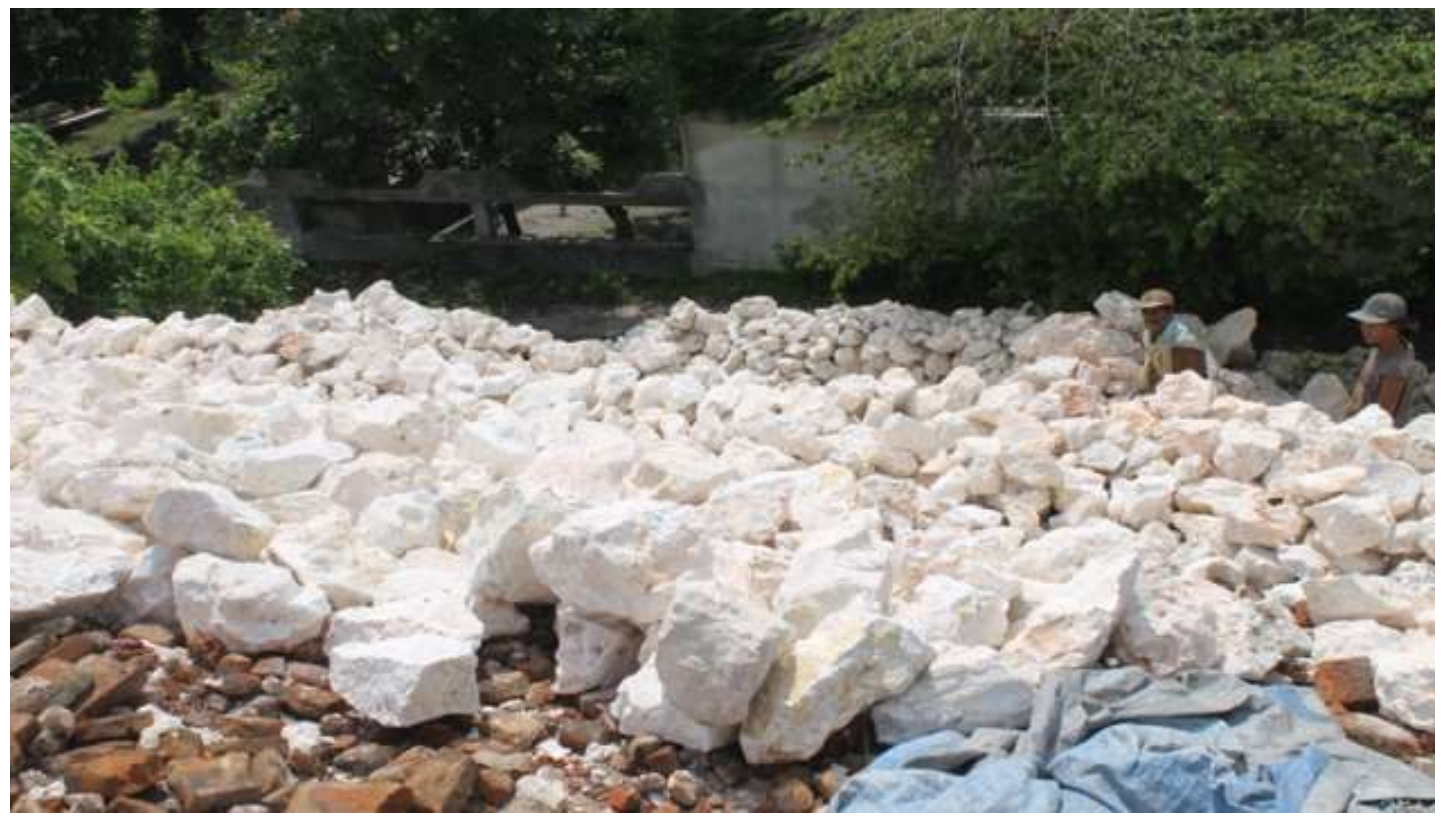

Gambar 1. batu kapur di Gunung Sadeng

Sama halnya dengan jawaban dari masyarakat, peneliti juga membandingkan jawaban masyarakat yang bersumber dari kuesioner yang di isi masyarakat atau warga yang berkerja sebagai penambang batu kapur di Gunung Sadeng dengan hasil penelitian yang dilakukan oleh Disperindag, hasil yang di dapat ternya sama penelitian yang dilakukan oleh Disperindag mengatakan bahwa jenis batu kapur yang ada di Gunung Sadeng berupa batu kapur berjenis (Chalky Limestone), batu kapur terumbu dan breksi batu kapur. Batu kapur Gunung Sadeng (Chalky Limestone) berwarna putih susu, merah muda dan putih kekuningan (warna lapuknya), lunak dan kurang padat mudah dihancurkan menjadi butiran yang lepas-lepas, struktur berlapis, besar butir berukuran lempung, kemas tertutup. Tersusun oleh kristal-kristal kalsit dan mempunyai kandungan fosil dalam batuan. Berdasarkan pengamatan secara megaskopis didapatkan lingkungan peng endapan berupa laguna (shelf lagoon) - terumbu belakang Back reef, diendapkan pada energi lemah. Batugamping terumbu dan breksi batugamping berwarna merah muda dan putih kekuningan, dengan lubang -lubang pelarutan yang menunjukkan adanya aktivitas pelarutan, sehingga memperlihatkan struktur berongga, bentuk permukaan meruncing/tajam dan berasosiasi dengan mangan. Sistem penambangan di Gunung Sadeng menggunakan sistem penambangan terbuka (Open Pit Minning), dengan kemeringan lereng 210- 250

Gunung Sadeng merupakan Gunung Kapur yang terletak di Kecamatan Puger, Kabupaten Jember, Jawa Timur. Gunung Sadeng memiliki potensi 
sumber daya alam berupa batu kapir yang di pergunakan oleh masyarakat Kecaatan Puger sebagai bahan dasar pembuatan semen, Gunung Sadeng di nilai layak oleh masyarakat Kecamatan Puger dijadikan wilayah penambangan. dengan alasan wilayah Gunung Sadeng menurut responden karena batu kapur tidak akan pernah habis dan alasan lainya karena batu Kapur sangat bermanfaat sebagai bahan dasar pembangunan salah satunya untuk bahan dasar pembuatan semen, mereka menganggap akan sangat di sayangkan bila Gunung Sadeng tidak dimanfaatkan. Dengan adanya Gunung Sadeng pekerjaan sebagai penambang batu kapur banyak diminati oleh masyarakat Kecamatan Puger alasan masyarakat Kecamatan Puger atau responden menekuni pekerjaan penam bang tidak ada pekerjaan lain selain menjadi penambang, yang dapat diartikan bahwa menjadi penambang merupakan pekerjaan utama dan satu-satunya, hal ini dikarenakan rata-rata penambang memiliki riwayat pendidikan yang rendah, sehingga tidak memiliki pilihan pekerjaan lain.

Lokasi penambangan merupak hal yang sangat penting bagi kegiatan penambangan, $78 \%$ penambang memilih jawaban lokasi penambangan yang digunakan untuk penambangan batu Kapur statusnya adalah sewa, lokasi tempat mereka menambang merupakan milik Pemerintah Daerah atau pemerintah Kabupaten Jember, sewa lokasi penam bangan dilakukan oleh PT/klompok penambangan yang merupakan penambang berskala besar, sedangkan 22\% lainya yaitu penambang bersekala kecil seperti pekerja tambang yang individual tidak menyewa lokasi penambangan karena mereka hanya menambang dengan skala kecil yang tidak begitu berpengaruh bagi sumberdaya Gunung Sadeng. kegiatan sewa menyewa lokasi penambangan juga berkaitan dengan mengenai perizinan penam bangan, 90\% responden memiih jawaban sudah melakukan perizinan penambangan pada Pemerintah Daerah atau pemerintah Kabupaten Jember, perizinan dilakukan oleh PT/Pabrik yang bergerak dalam bidang penambangan yang ada di sekitar Gunung Sadeng atau sekitar daerah penambangan yang merupakan penambanga skala besar dan berapa penambanga skala kecil, sedangkan $10 \%$ lainya tidak melalukan perizinan.

\subsection{Proses penamabangan batu kapur di Gunung Sadeng}

Kegiatan penambangan dilakukan oleh para penambang sebanyak 52\% memilih jawaban 3 kali dalam sehari melukan penambangan, dilakukan oleh pekerja tambang yang bekerja pada pabrik tambang yang sudah diatur waktu penambangan dan seberapa banyak batu kapur yang harus mereka dapatka dalam waktu 1 hari sedangkan 48\% penambang lainya ada yang kurang dari 3 kali ada juga yang lebih dari 3 kali karena mereka tergabung dalam kelompok 
tambang maupun pekerja tambang individual yang dapat menetukan berapa kali dalam sehari melakukan penambangan. proses penam bangan di Gunung Sadeng, terdiri dari 7 tahap, antara lain tahap tersebut (1). Tahap penyelidikan (2). Pembabatan dan penebangan (3). Pengupasan lapisan tanah penutup (4) penggalian dan pembe rairan (5). Pemuatan (6). Pengangkutan (7). Pembakaran

Teknik penambangan merupakan cara yang digunakan pnambang untuk menambanga batu kapur sebanyak 53\% responden menggunakan teknik penam bangan terbuka, teknik penambangan terbuka banyak digunakan oleh penambang batu kapur Gunung Sadeng karena mereka menggunakan bom atau alat peledak untuk mencari bongkahan batu kapur selain itu tempat penambangan yang berada di lereng gunung dan memiliki ketinggian membuat mereka harus menggunakan penam bangan terbuka, sedangkan 22\% responden lainya memilih penambangan dalam karena mereka adalah penambang kecil yang mengandalkan alat tradisional dan hanya menambang sekala kecil, adapun $25 \%$ responden penambang yang memilih teknik penambangan dalam dan penambangan terbuka

\subsection{Dampak ekologi penambangan batu kapur di Gunung Sadeng}

Bukan hanya mengancam keselamatan, maupun kelestarian hewan dan tumbuhan kegiatan penambangan dapat berdampak negatif bagi sesama manusia bahkan dirinya sendi, kegiatan yang dapat membahayakan yaiu memanjat tebih kapur yang terbukti dengan jatuhnya korban yang meninggal karna terjatuh dari ketinggian, runtuhnya bebatuan kapur dari atas tebing yang menimpa para penbang dan menyebabkan kematian, tergangunya sistem pernapasan karena debu akibat penambangan dan asap akibat pembakaran batu gamping juga menjadi acaman bagi para penambang, hal ini terbukti dengan wawancara peneliti dengan para penambang yang ada di Gunung Sadeng, sosusi yang dapat digunakan adalah dengan memakai perlengkapan penambangana, contoh baju yang khusus untuk para penambang, helem agar aman dari reruntuhan batu kapur, masker agar asap dan debu tidak langsung masuk kesaluran pernapasan para penambang.

Berbagai kegiatan manusia tidak hanya kegiatan positif yang dapat melestarikan fauna, adapun kegiatan manusia yang justru mengacam bahkan merusak kelestarian fauna, kegiatan tersebut salah satunya adalah kegiatan penambangan, lebih tepatnya kegiatan penambangan batu kapur di Gunung Sadeng, kegiatan penambangan memiliki beberapa proses yang dapat mengacam kelestarian fauna, contohnya kegiatan pembabatan Vegetasi, pengupasan tanah dan pembakaran batu kapur, contoh proses penambangan 
tersebut dapat merusak habitat fauna yang ada di Gunung Sadeng, akibatnya fauna seperti burung, serangga dan fauna lainya sedikit demi sedikit berkurang keberadaannya karna tempat tinggal mereka seperti vegetasi telah beruba menjadi lahan pertambangan.

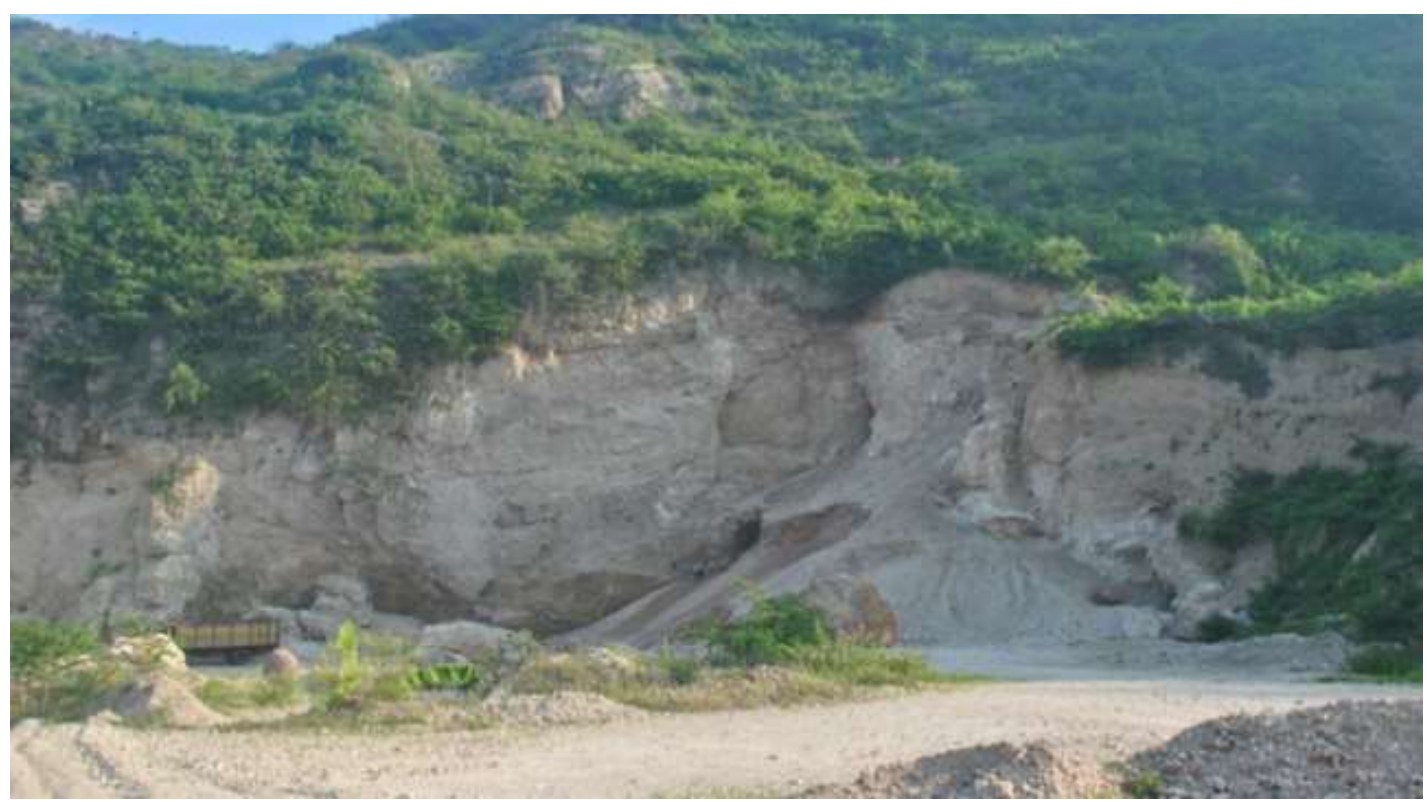

Gambar 2. Dampak Kerusakan Penambangan

Kerusakan habitat tumbuhan yang ada di Gunung Sadeng, hal ini dikarnakan proses penambangan berupa pengupasan dimana dalam prosesnya tumbuhan berupa semak dan pepohonan ditebang agar tidak menghalangi proses penam bangan batu kapur, proses yang lainya seperti pengupasan dan penggalian juga merusak kelestarian tumbuhan, seperti gambar DIATAS terlihat perbedaan antaraa bagian atas dan bagian bawah Gunung Sadeng, bagian atas terlihat berwarna hijau menandakan masih banyak tumbuhan yang masih tumbuh dan berkembang karna bagian atas masih belum tersentuh oleh kegiatan penambangan, sedangkan bagian bawah berwarna putih menandakan lapisan tanah bagian luar sudah terkelupas karna proses penambangan berupa bembabatan tumbuhan dan pengupasan tanah. Dampak yang dapat terjadi yaitu tidak dapat kembalinya komdisi seperti semula, dapat mnyebabkan kelongsoran, solusi yang dapat dilakuakan denagan menutup kembali dengan tanah agar lapisan atas kembali ditmbuhi tumbuhan.

Kegiatan pengupasan tanah adalah salah satu tahapan pada proses penam- bangan dimana dalam proses tersebut lapisan tanah paling atas dikupas atau diambil agar lapisan tanah terpisah dari bahan tambang yaitu batu kapur, akibat yang bisa terjadi tanah erosi dan tanah longsor, karna sifat 
fisik, kimia, dan biologi tanah sudah tidak seperti semula lagi sebelum dilakukanya proses pengupasan tanah yang diakibatkan oleh proses penambangan teutama yang langsung berkaitan dengan tanah, misalnya pengupasan tanah, penge boman, pembabatan vegetasi yang dapat mempengaruhi sifat fisik, kimia, dan biologi tanah.

Proses penambangan salah satunya adalah membuat lubang sebagai cara untuk memudahkan penambangan dalam mencari bahan tambang, namun pada saat musim penghujan lubang dari bekas penambanga akan terisi air dan menjadi sarang nyamuk yang dapat membahayakan penambang maupun warga yang bermukim disekitar lokasi tambang, agar lubang tidak tegenang air dan agar nyamuk tidak bersarang pada lubang yang terisi air tersebut, tindakan yang dapat dilakukan adalah dengan menutup lubang akibat proses penambangan agar tidk tergenangi air, dan agar nyamuk juga tidak bersarng dan berkembangbiak.

Pencemaran udara adalah masuknya atau dimasukkannya zat, energi, atau komponen lain ke dalam udara ambien oleh kegiatan manusia, sehingga mutu udara ambien turun sampai ketingkat tertentu yang menyebabkan udara ambien tidak dapat memenuhi fungsinya. Berkaitan dengan peraturan pemenritah mengenai pencemaran udara resebut, dapat dikatakan kegiatan pembakaran batu kapur mencemari udara karena sudah memasukan zat atau energi lain kedalam udara yang berwarna hitam dan pekat yang tidak sesuai dengan peraturan pemerintah no 41 tahun 1999

\section{Simpulan dan Saran}

Berdasarkan hasil analisis data dan pembahasan maka dapat ditarik kesimupaln yaitu jenis batu Kapur di Gunung Sadeng, Kecamatan Puger yaitu Chalky linestone, yang merupakan sebuah batu Kapur lembut dengan tekstur yang sangat halus, berwarna putih keabu-abuan. Batuan ini terbentuk terutama dari cangkang berkapur organisme laut mikroskopis seperti foraminifera atau dari berbagai jenis ganggang laut.Dan adanya batu Kapur jenis Chalky limestone di Gunung Sadeng dimanfaatkan oleh para penambang sebagai bahan dasar pembuatan semen dengan mengambilnya rata-rata lebih dari 1 kwintal dalam satu hari. Proses penambangan batu kapur di Gunung Sadeng terdiri dari beberapa tahapan antara lain tahap penyelidikan, tahap pembabatan dan penebangan, tahap pengupasan lapisan tanah penutup, tahap penggalian dan pemberairan, tahap pemuatan, tahap pengangkutan dan tahap pembakaran yang kurang memper- hatikan lingkunan dalam melaku kan tahap demi tahap proses penambangan, walaupun demikian ada beberapa hal yang mendu kung terlaksananya proses penam bangan di Gunung Sadeng, antara lain 
karakteristik wilayah Gunung Sadeng yang mendukung di laksanakanya proses penam bangan, faktor pendukung yang mempengaruhi kegiatan penam bangan, kepemilikan lokasi penambangan, Izin penambangan yang mendukung terlaksananya proses penambangan di Gunung Sadeng. Dampak ekologi penambangan batu kapur bagi unsur biotik relatif kurang baik, bagi manusia proses penambangan dapat mengganggu aktifitas sehari-hari bahkan meng ganggu kesehatan masyarakat maupun pkerja tambang itu sendiri, bagi flora atau tumbuhan kegiatan penambangan sanagt merugikan karna habitat flora menjadi rusak dan tercemar karna proses penambangan, bagi fauna proses penambangan sangat menggagu habitatnya yang berdampak pada kelestarianya. Dampak bagi unsur abiotik, antara lain bagi tanah proses penambangan dapat meng ganggu kesuburan tanah karna tanah yang semula ditanami banyak vegetasi semakin lama vegetasi semakin habis dan tanah mudah longsor, mudah tercemar karena unsur haranya tidak sebaik pada saat kondisi aal sebelu adanya proses penambangan, bagi air pada saat musim penghujan air mudah keruh dan tegenang dimana-mana, pada saat musim kemarau air mudah langka karena vegetasi Gunung Sadeng sudah dibabat akibat proses penam bangan, baggi udara proses penambanga membaa dampak buruk terutama pada proses pembakaran batu kapur, solusi dapat dilakukan adalah dengan tetap mengutamakan lingkungan dalam kondisi apapun dalam proses penambangan.

Saran yang dapat dikemukakan perlunya kegiatan gotong royong bagi sesama pekerja tambang maupun pihak lain yang terkait dengan penambangan untuk sama-sama menjaga lingkungan Gunung Sadeng misalnya mengebalikan kembali tanah yang sudah dikupas atau yang sudah digali ke tempat semula agar vegetasi bisa tumbuh kembali dan berfungsi sebagaimana mestinya agar penambangan batu kapur bisa terus berlangsung dan bisa dinikmati generasi yang akan datang dengan keadaan lingkungan yang tetap terjaga. Keikutsertaan pemerintah dalam menjaga kelestarian Gunung Sadeng agar masyarakat Kecamatan Puger tidak hanya merasakan manfaat ekonomi nya saja namun juga manfaat lingkungannya juga, misalnya memberikan penyuluhan kepada warga yang bekerja sebagai penambang agar dapat mengetahui bagaimana menambang yang benar tanpa harus merusak lingkungan.

\section{Daftar Rujukan}

Algunadi, I., Astawa, I. M., \& S. (2010). Analisis Dampak Penambangan Batu Kapur Terhadap Lingkungan di Kecamatan Nusa Penida. Jurnal Bencana 
Dan Lingkungan Geologi, 1-13.

Arikunto, S. (2011). Prosedur Penelitian Suatu Pendekatan Praktik. Jakarta: Rineka Cipta.

Bapeda Jember. (2009). Gambaran umum Gunung Sadeng, Kecamatan Puger, Kabupaten Jember.

Busroh, H. F. freaddy. (2014). KBIJAKSANAAN PENGELOLAAN LINGKUNGAN HIDUP DAN PENATAAN RUANG. Ilmu Hukum, 1(1), 9-14.

Hakim, M. R. (2015). Model Pengelolaan Lingkungan Pertambangan Batu Kapur Terhadap Potensi Kerusakan Lingkungan dan Sikap Masyarakat di Gunung Jadih Desa Parseh Kecamatan Socah Kabupaten Bangkalan. Bencana Dan Lingkungan Geologi, 1-7.

Manik, N. (2010). Pengolahan pertambangan yang berdampak lingkungan di Indonesia. IndonesiaJurnal Bencana Dan Lingkungan Geologi, 10(11), 1-12.

Maskuri, F. (2010). Indentifikasi bahan galian dalam metode eksplorasi awal. Jurnal Ilmiah $M P G, 3(1), 1-10$.

Purnaweni Hartuti. (2014). KEBIJAKAN PENGELOLAAN LINGKUNGAN DI KAWASAN KENDENG UTARA PROVINSI JAWA TENGAH. Ilmu Lingkungan, 12(1), 53-65.

Satriyani, D. A. (2014). Studi Tentang Kondisi Sosial Ekonomi Penambangan Kapur di Gunung Sadeng Kecamatan Puger Kabupaten Jember. Sosio Ekonomi, 1-8.

Sugiyono. (2011). Statistika Untuk Penelitian. Bandung: CV Alfabeta. 